
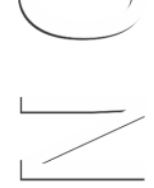

\title{
ADI 4277- DF: \\ Tendências discursivas no reconhecimento e equiparação das \\ Tendências discursivas no reconhecimento e equiparação das
relações entre pessoas do mesmo sexo no Brasil
}

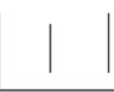

Fabrício Marcelo Vijales ${ }^{1}$

Pontifícia Universidade Católica do Rio Grande do Sul

Resumo: A proposta é analisar, por meio dos discursos contrários e favoráveis, o julgamento da ADI 4277-DF e os ganhos com a decisão. No entanto, a barreira que se quer ultrapassar é a de um modelo de família tradicional. Se, por um lado, houve ganhos, por outro, a decisão deixa de avançar no reconhecimento efetivo de culturas e identidades diversas e para outros núcleos familiares. Do ponto de vista teórico, a pesquisa é construída com alicerce na teoria da rotulação, do etiquetamento e no empreendimento de normas para demonstrar como o transvio é construído a partir da adesão de indivíduos a um padrão de comportamento desviante de forma sequencial. No plano metodológico, os dados são analisados a partir da Análise Crítica do Discurso, com foco nas formas de abuso de poder e ideologias para o estudo de como os discursos sofrem influências sociais e legais, como processos de normalização de condutas resultam em desigualdades sociais. Na polarização dos grupos em disputa, encontramos diferentes forças agindo na manutenção de regras que regulamentam a relação entre pessoas do mesmo sexo, frente à naturalização da família e baseada em um suposto único modelo compreendido na exegese constitucional até o momento do julgamento.

Palavras-chave: equiparação; família; discurso; rotulação; normas. 


\title{
ADI 4277- DF: \\ Discursive tendencies in the recognition and leveling of relations between people of the same sex in Brazil
}

\begin{abstract}
Our goal is to analyze, in the speeches around the Supreme Court's decision on homoerotic relationships, the articulation of ideologies and advances in the perspective of recognition of these relationships in Brazil. The research is built on the theory of labeling, demonstrating how the deviation is built through the implementation of concepts of normality in society, defining the relationship between people of the same sex as an abnormality. The speeches are analyzed through the Critical Discourse Analysis, focusing on forms of abuse of power to study how discourses are inserted in society and result in social inequalities. The goal is to analyze, in the polarization of groups, how the progressive and conservative discourses articulate recognition of marriage between same sex, or define it as a deviation from the traditional notion of family. Through the discourse analysis, this study seeks to deepen, critically, the procedures of the action of developing the labeling, through the production of oral and written discourses, by which interpretations are built and shared by the institutions and social forces in the construction of the relationship between people of the same sex as a deviation.
\end{abstract}

Keywords: recognition; homoerotism; speech; labeling; family.

\section{ADI 4277- DF: \\ Tendencias discursivas en el reconocimiento e igualación de las relaciones entre personas del mismo sexo en Brasil}

\begin{abstract}
Resumen: La propuesta es analizar, a través de discursos contrarios y favorables, la sentencia de ADI 4277-DF y las ganancias de la decisión. Sin embargo, la barrera a superar es la de un modelo familiar tradicional. Si, por un lado, hubo avances, por el otro, la decisión no avanza en el reconocimiento efectivo de las diversas culturas e identidades y de otros núcleos familiares. Desde un punto de vista teórico, la investigación se basa en la teoría del etiquetado, el etiquetado y el cumplimiento de estándares para demostrar cómo se construye el cambio de la adhesión de los individuos a un patrón de comportamiento desviado de manera secuencial. A nivel metodológico, los datos son analizados a partir del Análisis Crítico del Discurso, enfocándose en las formas de abuso de poder e ideologías para el estudio de cómo los discursos sufren influencias sociales y legales, ya que los procesos de normalización de la conducta resultan en desigualdades sociales. En la polarización de los grupos en disputa, encontramos diferentes fuerzas actuando en el mantenimiento de reglas que regulan la relación entre personas del mismo sexo, en vista de la naturalización de la familia y en base a un supuesto modelo único entendido en la exégesis constitucional hasta el momento del juicio.
\end{abstract}

Palabras clave: coincidencia; familia; habla; letras; estándares. 


\section{Introduzindo o debate}

$\mathrm{E}$ sta pesquisa tem por objetivo analisar, através de discursos contrários e favoráveis, de que forma o julgamento da ADI 4277-DF (BRASIL, 2011) representa um avanço no reconhecimento da relação entre pessoas do mesmo sexo no Brasil. Considerando todo o contexto em que os discursos se inserem, a hipótese é de que a equiparação à família é construída por meio de um conceito de família tradicional baseado no casamento heterossexual (BUNCHAFT; CRISTIANETTI, 2016)². A decisão altera o filtro de percepção do significado desses acontecimentos, mas não afasta o caráter anatomofisiológico ao conceito de família expresso na Constituição. Assim, a principal pergunta a ser respondida é: de que maneira os discursos emanados da ADI 4277-DF (BRASIL, 2011) impactam a questão da identidade de indivíduos pertencentes a famílias homoparentais?

Os debates em torno da decisão judicial têm como núcleo o artigo art. 226 da Constituição Federal de 1988. Esse dispositivo legal vinha sendo interpretado de forma literal, resumindo a família ao sexo biológico. O texto apresenta os seguintes termos: "a família, base da sociedade, tem especial proteção do Estado". E no parágrafo $\S 3^{0}$ exemplifica: "para efeito da proteção do Estado, é reconhecida a união estável entre o homem e a mulher como entidade familiar, devendo a lei facilitar sua conversão em casamento" (BRASIL, 1988).

Casamento, segundo o artigo 226 da Constituição Federal de 1988, pressupõe a diversidade de sexo, tendo como protagonistas da base nuclear familiar o homem e a mulher. Trata-se de um contrato em que o legislador não se preocupou com definir características específicas ao conceito de casamento, apenas delimitou como pressuposto básico a comunhão pela vida.

Para o direito, família é um conceito em mutação que assumiu características tradicionais. É o que se pode constatar a partir da conceituação de Rolf Madaleno (2015: 36) "a família matrimonializada, patriarcal, hierarquizada, heteroparental, biológica, institucional vista como unidade de produção", muito embora esse conceito já tenha sido superado no entendimento de grande parte dos doutrinadores.

\footnotetext{
${ }^{2}$ Os debates em torno da decisão judicial têm como núcleo o artigo art. 226 da Constituição Federal de 1988. Este dispositivo legal vinha sendo interpretado de forma literal resumindo a família à relação entre homem e mulher, reduzidos ao sexo biológico. O texto apresenta os seguintes termos: "a família, base da sociedade, tem especial proteção do Estado". E no parágrafo $\S 3^{\circ}$ exemplifica: "para efeito da proteção do Estado, é reconhecida a união estável entre o homem e a mulher como entidade familiar, devendo a lei facilitar sua conversão em casamento" (BRASIL, 1988). Estas figuras são portas que dão acesso ao importante debate sobre família e as diferenças sexuais e sua construção como uma exigência social e jurídica que passa a ser oposta dentro dos debates na decisão judicial. Para o direito, a sociedade de fato, casamento e união estável são termos distintos que implicam em uma série de efeitos sobre o patrimônio e a regulamentação das relações afetivas. A sociedade de fato foi reconhecida na ausência de uma legislação específica como um recurso para regulamentar o patrimônio dessas relações. No entanto, os efeitos são limitados a uma parceria de negócios, diferenciando de uma união estável que é a relação entre homem e mulher pública e duradoura com o objetivo de constituir família, e seus efeitos são equiparados ao regime de comunhão parcial de bens, em uma situação de internação hospitalar, visitas ocupa uma posição distinta e oposta em relação à união estável. No caso da união estável prevista no artigo 1.723“ descreve que é reconhecida como entidade familiar a união estável entre homem e mulher, devendo a lei facilitar sua conversão em casamento, configurada pela convivência pública, contínua e duradoura estabelecida com o objetivo de constituição de família”. O novo Código Civil, nos artigos 1.723/1.727 e 1.79o, estabelece os requisitos fundamentais para a constituição da união estável entre homem e mulher, assim como seus efeitos patrimoniais por motivo de dissolução por convenção entre os conviventes ou pela morte de um deles. Já o casamento, segundo o artigo 226 da Constituição Federal de 1988, pressupõe a diversidade de sexo, tendo como protagonistas da base nuclear familiar o homem e a mulher. Trata-se de um contrato onde o legislador não se preocupou com definir características específicas ao conceito de casamento, apenas delimitou como pressuposto básico a comunhão pela de vida. Os regimes dessa comunhão é que irão determinar a relação do direito patrimonial.
} 
No entanto, uma família não é uma constante biológica e sua forma está sujeita a mudanças permanentes (HONNETH, 2014) e pode ser considerada como um grupo de pessoas unidas por laços no qual adultos assumem a responsabilidade de cuidar de crianças (GIDDENS, 2004) ${ }^{3}$.

Segundo Judith Butler (2003: 224), o estado exerce poderes de normalização, principalmente quando condiciona ou limita os debates sobre casamento. Variações no parentesco que se afastem de formas diádicas de família heterossexual garantidas pelo juramento do casamento e qualquer outra forma colocam em risco as leis consideradas naturais.

A reivindicação do casamento por homossexuais problematiza posições políticas em torno da família e do casamento, que em grande medida foram implementados pela ordem médica como forma de empreendimento na construção do desvio (COSTA, 1999), ou seja, informar que a homossexualidade é patológica frente ao modelo de família tradicional. O resultado foi a naturalização da relação casamento/família entre o homem e a mulher como normal e o homoerotismo como estranho.

A relativização das normas que determinam a normalidade leva a refletir sobre a construção com base nos costumes estabelecidos ao longo de um processo de julgamento e de disputas entre grupos progressistas e conservadores. A homoafetividade foi construída de forma negativa por ameaçar o estabelecimento das relações de gênero binárias e hierarquizadas dentro de sistemas patriarcais padronizados de forma universal. Segundo Roger Raupp Rios (2014), a formulação da expressão homoafetividade, ainda que bem-intencionada, mostra uma tentativa de adequação à norma, subordinando, ainda, princípios como o da liberdade, igualdade e não discriminação. Se, por um lado, a norma das relações afetivas resultou de valores, ideologias e políticas conservadoras, por outro, as leis tiveram um papel fundamental no processo institucionalizado de rotulação em função da interpretação dada ao texto legal. Adotaremos, portanto o termo homoerótico, o que permite uma postura mais crítica frente aos aspectos negativos da sexualidade implícitos na ADI 4277- DF.

Se por um lado a ordem médica teve influência na construção cultural da família, por outro lado, a concepção da relação entre pessoas do mesmo sexo como pecado está fundada no discurso judaico-cristão, articulou um juízo condenatório. No casamento, com deveres de obediência na consagração da família constituída pela fé. Sobre os cônjuges, as prescrições normativas eram carregadas de recomendações (FOUCAULT, 1988).

O essencialismo biológico, conceito retirado da desconstrução promovida pelo movimento feminista (CITELLLI, 2001; PARISOTTO, 2003), é o estandarte da ideologia cristã que vê a desorganização social contrária à "ordem natural”, que nada mais é do que um determinismo biológico, aplicado às relações de gênero em que predominam papéis específicos próprios para homens e mulheres. Impensável dentro de um núcleo familiar constituído por outros arranjos parentais.

É o que esclarecem Oliveira e Duque (2013: 141):

Em relação a esse esforço de compreensão desnaturalizante, cabe pensar em que medida uma compreensão de família baseada em critérios puramente "biológicos", ou que assim se pretende, é antes um argumento de cunho político-ideológico do que cientificamente fundamentados. A família enquanto uma instituição social é antes produto de relações históricas, políticas e econômicas, ideologicamente marcadas, do que fruto de uma "natureza" ontologicamente estabelecida e pré-determinada.

3 Além disso, há várias definições/ reconfigurações da família contemporaneamente que envolvem outros modelos como os de família monoparental, re-constituída ou recomposta. 
Por estes argumentos, a legislação permaneceu omissa à extensão dos direitos a população LGBT. O entendimento dos tribunais seguiu a mesma tendência e, em alguns casos, foi enfático ao descrever a homossexualidade como um desvio de conduta ou problema de personalidade seguindo a tradição da homossexualidade como doença. A definição de "direito" é considerada "parte do grupo de fenômenos que pertencem ao âmbito da linguagem, dos discursos que circulam socialmente" (CORREAS, 1996: 43). Para melhor compreender o tema da produção de sujeitos através dos discursos jurídicos, Rios e Oliveira (2012: 251) completam:

\begin{abstract}
Esta dinâmica pode ser observada em muitos domínios do direito positivo estatal, tais como o direito de família e o direito penal relativo aos crimes sexuais. Para tanto concorrem o legislador, o processo político parlamentar, a "doutrina jurídica” (formada pelo trabalho de reflexão e comentário por parte de acadêmicos e profissionais do direito, em face do direito positivo e da jurisprudência) e a jurisprudência (conjunto de decisões proferidas pelos diversos tribunais e instâncias do Poder Judiciário a respeito de determinado tema).
\end{abstract}

De um lado, há uma sustentação radical de que a homossexualidade é contrária à condição humana, de outro uma posição mais tolerante a que pessoas tenham tendências homossexuais e não pratiquem atos sexuais. Ainda há a posição de que o reconhecimento do casamento homossexual seria um exagero, tendo em vista os danos que a medida "[...] pode causar à instituição familiar" (RIOS in RIOS; GOLIN; LEIVAS, 2011: 72).

É o que se constata no discurso do representante da Conferência Nacional dos Bispos do Brasil (CNBB) sobre o julgamento da ADI 4277- DF, Hugo José de Oliveira: "Polígamos, incestuosos. Alegrai-vos" (JUSTIÇA, 2011), ao iniciar sua defesa nos ditames da Igreja Católica que condena a homossexualidade desde o seu entendimento da sodomia como um pecado herdado de "Sodoma e Gomorra".

Ao referir "Polígamos, incestuosos. Alegrai-vos" em sua linguagem retórica, Hugo declara o pegador como possível a procedência da decisão, ao mesmo tempo em que suas palavras surgem como uma ameaça à condenação divina e dá as costas aos atos homossexuais em um processo de condenação ao inferno pelo pecado. Da mesma forma, pela Associação Eduardo Banks falou o advogado Ralph Anzolin Lichote: "Esse julgamento pode ter consequências inimagináveis para todos se dermos um passo errado" (JUSTIÇA, 2011).

É corriqueira a associação com essa referência anatomofisiológica na linguagem cotidiana quando a assunto entoa no cenário público. "Deus criou Adão e Eva e não Adão e Ivo" foi a frase do deputado federal Victório Galli (PSC) durante um evento organizado pelo governador de Mato Grosso4. Ou, ainda, "filho gay é falta de porrada", como bradou o então deputado Jair Bolsonaro (PP-RJ). Reverbera na mídia um discurso presente em nossa cândida sociedade de que ter filho gay é consequência de falta porrada de durante a infância5.

Os discursos que são acionados na decisão estão impregnados da cultura popular que tem reflexos diretos no processo de interação social. Inúmeros modos de construção das formas de sexualidade dos indivíduos são ajustados a partir dos "parâmetros" ideológicos da heterossexualidade.

\footnotetext{
4 Ver: "Deus criou Adão e Eva e não Adão e Ivo", diz deputado sobre casamento gay. Disponível em: < http://www.hipernoticias.com.br/autos/politica/deus-criou-adao-e-eva-e-nao-adao-e-ivo-diz-deputado-sobre-casamento-gay/45642>.

5 Ver: "Filho gay é falta de porrada". Disponível em: <http://www.pragmatismopolitico.com.br/2014/o3/ter-filho-gay-efalta-de-porrada-diz-bolsonaro.html $>$. Acesso em: 15 ago. 2019.
} 
O controle é exercido por meio da normatização e interferência na vida privado-pública. Esse cenário legal-normativo, ajuda-nos a pensar sobre o não reconhecimento como núcleos familiares, as famílias homoparentais pelo Estado por decorrência do discurso de representação de papéis de gênero:

\footnotetext{
observamos nesse discurso uma representação de papéis de gênero tal como normatizado pela sociedade heteronormativa, em que homens e mulheres possuem não apenas identidades fixas, mas também papéis/funções correspondentes e que devem ser "preservados" por um Estado policialesco e discriminatório. (OLIVEIRA e BECKER, 2018: 19)
}

Portanto, o jogo de interesses em questão no processo de reconhecimento está ordenado pela tradição em torno do conceito de família e ostentado pela "primazia" da heterossexualidade como um padrão único de conduta. Os mecanismos acionados na defesa e ataques argumentativos relatam, nos discursos, a relação entre pessoas do mesmo sexo como uma ameaça.

O Estado se depara, assim, com sua própria fragilidade. A herança de imposição de regras e rotulações deixada por nossos antepassados, que define a homoparentalidade como um desvio, revela a construção de um conjunto de normalização da família com base em uma ideologia romântica, mas não só. O afeto é a porta de acesso à interpretação discursiva que permite analisar a relação à sexualidade e às diferenças de gênero.

Se a possibilidade é a equiparação, mesmo que por unanimidade dos votos dos ministros, como tornar a homossexualidade aceita? $\mathrm{O}$ argumento segue na linha de que a homossexualidade é uma perversão. A solução encontrada na decisão é equiparar as relações homoafetivas às relações heteroafetivas.

A imagem dos casais homossexuais, rotuladas por atos estatais, pela religião, pelo direito e por um conjunto de doutrinas científicas que organizaram os saberes científicos de forma estratégica em detrimento à identidade de gênero e orientação sexual. Portanto, entendemos que questões relacionadas com o casamento e homoparentalidade representam a última fronteira de uma definição de normas que permaneciam naturais, não políticas e não históricas.

Assim, o tema chegou ao Supremo Tribunal Federal (STF) para julgamento.

\section{Princípios teóricos e metodológicos}

A teoria da rotulação (Labeling Approach) contribuiu para a remoção do véu que revestia o desdobramento de um complexo sistema de empreendimento de regras observados na ADI 4277- DF. Segundo Becker (2008: 15), "Quando uma regra é imposta, a pessoa que presumivelmente a infringiu pode ser vista como um tipo especial, alguém de quem não se espera viver de acordo com regras estipuladas pelo grupo. Essa pessoa é encarada com um outsider”.

O indivíduo que transgride a norma é identificado por um complexo esquema de ajustamento que determina, de forma cuidadosa, a categoria de comportamento que não é própria dos processos de sociabilização do mesmo, do ponto de vista da normalidade convencionada. A discrepância entre a identidade social informada de um indivíduo e a forma de reconhecimento dos símbolos criados para o estabelecimento da diferença é um meio de informar que os sujeitos apresentam sinais que os categorizam (GOFFMAN, 1988), tendo como referência normativa um comportamento que ele transgrediu, com base no esquema de crenças, valorações morais (MACHADO, 1991) como a identificação de comportamentos considerados sexualmente incompatíveis aos olhos daqueles que estão envolvidos na 
criação e na manutenção das normas. Portanto, "se um ato é ou não desviante, depende de como as outras pessoas reagem a ele" (BECKER, 2008: 24).

$\mathrm{Na}$ aplicação da metodologia, utiliza-se a Análise Crítica do Discurso (ACD) que dialoga com este trabalho à medida que os conceitos da análise são formulados por meio de noções fundamentais das Ciências Sociais (DIJK, 2012; FAIRCLOUGH, 2001; WODAK, 2004). Não existe uma divisão específica dos construtos do texto para realização da análise. O pesquisador pode desenvolver, com base no objeto tratado, seus próprios campos de análise. Na Análise Crítica do Discurso existe uma postura interdisciplinar, o que Dijk (2012) denomina de pluralismo metodológico, de modo que pode ter seu foco na análise gramatical, na retórica, na estilística, nas estruturas específicas de gênero, nas narrativas ou argumentações e, ainda, na análise convencional da fala e da interação.

Além disso, o quadro metodológico pressupõe que a produção discursiva seja mapeada também pela produção inconsciente de normas que contribuem para a desigualdade social, em conformidade com os conceitos de cognição e ideologias (DIJK, 2012), sobretudo no que diz respeito à contribuição do foco analítico no que se refere às estruturas discursivas polarizadas, cujo papel é crucial na expressão, na aquisição, na confirmação e, portanto, na reprodução das desigualdades.

Durante a análise foram identificados os posicionamentos polarizados e o sentido atribuído pelos atores sociais e juristas ao conceito de entidade familiar. Quanto aos grupos em disputa, encontrou-se diferentes forças agindo na manutenção dos seus argumentos. Esses grupos estão representados na disputa entre diferentes conjuntos de forças sociais, progressistas e conservadoras, que são bastante heterogêneos em seu interior.

Preliminarmente, as categorias de análise foram escolhidas por meio das posições discursivas assumidas. Posteriormente, selecionaram-se as categorias a partir das configurações discursivas tendo em vista o problema social, delimitando tensões, diferenças e opiniões expressadas; em seguida, selecionou-se o conflito dentro dos argumentos e, por fim, realizou-se a análise dos espaços semânticos presentes nos segmentos discursivos a fim de perceber os desajustes metafóricos e polarizações.

Assim, os dados coletados revelaram que a decisão trazia dois conjuntos de informações: de um lado uma descrição dos fatos emanados do meio social carregados de empreendimento de regras sociais que evidenciam o que está em jogo na decisão, que é a equiparação dos casais homossexuais ao conceito de família, bem como sua relação com o binarismo homem/mulher, e a noção de pertencimento ou não ao conceito de família trazido na Constituição Federal. Por outro lado, com base no sentido de validade que a norma emana, e que provém de uma herança cultural-histórica, os dados revelaram a representação distintiva da questão LGBT no âmbito da decisão, que mostraram camadas distintas de intolerância. Para tal, dividimos o conjunto de análise em dois eixos:

O eixo "A" analisou os dados pertencentes ao discurso emanado da pressão social para a mudança do paradigma da tradicional concepção de família. Surgiram configurações da noção de pertencimento ou não, as atribuições de significado aos pares, as categorias e os elementos de distinção de entidade familiar.

No eixo "B" o objetivo foi identificar os temas tangentes ao discurso do reconhecimento e da equiparação das relações. O controle exercido na disputa judicial, a fim de revelar padrões morais, crenças, ideologias e valores públicos que são convencionados na medida dos interesses. O objetivo foi o mapeamento das regras em torno dessa "teia social” presente no debate, na forma de ação, e na 
interação social, o comportamento sexual e à produção de um novo entendimento normativo.

Do objeto de análise o documento/decisão ADI 4277- DF surgiram, os seguintes temas denominados marcador discursivo: diferenciação, amor romântico, reação conservadora, religião/crença, antinaturalidade e familismo. Desse grupo, analisamos a performatividade que acentua a produção do sujeito como obra em particular dos sistemas jurídicos.

Buscamos os fatores determinantes das regras que estabelecem as relações que possivelmente reforçam ou mitigam subordinação, ao equipara o casamento homoerótico ao heteroafetivo. Ter acesso ao conteúdo dos discursos é uma forma de conhecer a interação social e aferir sobre os processos que determinam grupos familiares como normais e outros como um desvio.

\section{Tendências discursivas no reconhecimento da equiparação no julgamento da ADI 4277-DF}

Embora as identidades sociais, os valores culturais e o discurso jurídico sejam partes diferentes quando teorizadas, na presente análise são relacionadas com a semiótica de misturar o sexual e o não sexual, os casais, os verdadeiros coabitantes e os simples conviventes sob o interdito de um modelo de família, casamento e sexualidade.

Esses marcadores discursivos representam obstáculos a serem transpostos para observar diferenças que embora existam, por se tratar de grupos muito heterogêneos e com culturas variáveis, não é suficiente para justificar distinguilos em lei. A interpretação rígida da Constituição que enaltece o caráter biológico da das relações de gênero constituída pelo homem e pela mulher produz a diferença social e faz surgir uma distinção produzida culturalmente constituindo pessoas de outra espécie que não pertencem à ordem material prevista e naturalizada na legislação.

O primeiro marcador discursivo é a diferenciação. Nos debates sobre a diferença, conservadores tendem a reafirmar a hierarquia da diferença. Em oposição, a igualdade isonômica é reivindicada por progressistas. Tudo o que parece ser inovação com relação à igualdade pode estar ligado à agenda conservadora com base na naturalização das diferenças. O ponto central destacado por Pierucci (1999, apud NUERNBERG, 2001: 299) é atribuição de juízo de valor, e acredita "que a crença da diferença possa se desvincular das relações de valor que fundamentam a desigualdade”.

O marcador discursivo diferenciação aparece no discurso como eixo de referência para análise dos debates sobre a diferença. Vejamos no discurso emanado no STF:

\footnotetext{
A diferença, embora sutil, reside no fato de que, apesar de semelhante em muitos aspectos à união estável entre pessoas de sexo distinto, especialmente no que tange ao vínculo afetivo, à publicidade e à duração no tempo, a união homossexual não se confunde com aquela, eis que, por definição legal, abarca, exclusivamente, casais de gênero diverso. (STF, 2011)
}

As políticas de reconhecimento e equiparação (HONNETH, 2003; FRASER, 2007) e justiça social tendem à valorização da diferença e não, simplesmente, pela definição legal, pois a diferença vem acompanhada, inseparavelmente, da pluralidade. Daí o desafio na decisão de estabelecer um entendimento sobre o reconhecimento e a equiparação no que toca às liberdades individuais e o coletivo, ou seja, reconstruir o geral incorporando a diferença, no caso das relações afetivas 
possíveis, não excluindo uma em detrimento de outras e produzindo formas de emancipação e autonomia para ambas.

De um lado, a trajetória permanente do empreendimento da diferenciação entre homossexuais e heterossexuais, de outro, a exigência de um reconhecimento à igualdade de direito e o reconhecimento de núcleos familiares dentro do ordenamento jurídico. $\mathrm{O}$ debate polarizado aparentemente representa construção, no entanto, deixa claro que a produção da diferença parte de conservadores que dão cores e significados à heteronormatividade vigente, discurso que está ligado diretamente à identidade familiar tradicional em que se fundem política e religião.

É a partir da diferença anatomofisiológica, estrategicamente prevista no texto constitucional, que a noção de diferença sexual como ato permissivo para o casamento, que se encontra o processo diferenciador construído historicamente. Em camadas mais profundas, é possível perceber a própria negativa da existência de outras configurações de núcleos familiares. A partir da constatação da existência, surge a abominação dentro de um cenário político e jurídico. Essa diferença sexual já vem sendo denunciada pelas feministas a partir da análise sexo/gênero com as categorias de homem e mulher (BUTLER, 2003; SCOTT, 1995).

Segundo Joan Wallach Scott (1995), por intermédio de pesquisas voltadas às relações entre homens e mulheres, os mecanismos de diferenciação social se tornaram evidentes pelos campos científico, biológico e religioso, ficando possível a identificação dos processos de diferenciação, hierarquização e inferiorização da mulher por meio deles. O movimento feminista buscou responder a perguntas relevantes, inicialmente trabalhando o significado conceitual da questão de gênero.

Endossando essa posição, Oliveira e Duque destacam que "precisamos compreender o papel da sociedade nestas novas percepções não naturalizantes e/ou não metafísicas da análise sobre sexo e gênero" (2013: 144). Nessa perspectiva destacamos que Butler, compreende sexo como parte de uma prática regulatória que produz os corpos que governa.

Nesse sentido:

\begin{abstract}
pois, o "sexo" não apenas funciona como uma norma, mas é parte de uma prática regulatória que produz os corpos que governa, isto é, toda força regulatória manifesta-se como uma espécie de poder produtivo, o poder de produzir - demarcar, fazer, circular, diferenciar - os corpos que ela controla. Assim, o "sexo" é um ideal regulatório cuja materialização é imposta: esta materialização ocorre (ou deixa de ocorrer) através de certas práticas altamente reguladas. Em outras palavras, o "sexo" é um constructo ideal que é forçosamente materializado através do tempo. Ele não é um simples fato ou a condição estática de um corpo, mas um processo pelo qual as normas regulatórias materializam o "sexo" e produzem essa materialização através de uma reiteração forçada destas normas. (BUTLER, 2001: 153)
\end{abstract}

A ausência de previsão legal explicita o heterossexismo do legislador (RIOS; OLIVEIRA, 2012) como diferenciação combatida pelo movimento LGBT em termos legais, civis, políticos e sociais. O reconhecimento das diferenças e equiparação que é alcançada na decisão representa um avanço significativo em termos de direito.

Inegável o estabelecimento de uma ordem heterossexual no que se refere à família. Partindo do princípio de que a diferença é um produto social, a família teve influência conservadora com seus interesses na reprodução, na economia e no controle social. É igualmente inegável que, muito embora, socialmente, o casamento gay já existisse e talvez em boa parte bem adaptadas ao meio social, o 
reconhecimento recusado por parte da legislação e, consequentemente, o direito, até a decisão, jogavam esses núcleos familiares nas periferias da sociedade.

Sexo entra no cenário dos debates e representa uma visão essencialista que classifica, diferencia e hierarquiza, organizando a sexualidade dentro do sistema binário e estabelecendo uma diferença que é assimilada pela maioria ou pela cultura dentro das relações de gênero compartilhadas. No entanto, não deve ser um critério de interpretação que estabeleça limites de direitos e que lance a toda sorte de hostilidade configurações familiares heterossexuais.

Os avanços em torno do reconhecimento jurídico para além das bases familiares matrimoniais, poderiam ter sido maiores, lançando mão do modelo binário para o entendimento de um novo núcleo familiar de fato, com suas próprias culturas. Mas, após o reconhecimento das relações homoeróticas como entidade familiar, os mecanismos que, por centenas de anos, normalizaram o conceito de família, permanecem no meio social dentro de grupos conservadores dispostos, como afirma Becker (2008), a empreender sua cruzada moral com base no poder que extraem de sua suposta posição superior na sociedade.

O segundo marcador discursivo é o amor romântico, a ação canônica que consagrou ao casamento entre o homem e a mulher a missão de procriar. O ideário de amor romântico que surge no discurso marcado de forma explícita como aporte na construção da equiparação. A construção da equiparação é ressignificada a partir da diferenciação, ou seja, seria o mesmo que dizer: iguais, porém diferentes. No entanto, em vez de reconhecer dentro de suas próprias particularidades, equipara. Assim, o homossexual deve se comportar como o casal heterossexual e sua expressão de sexualidade, equiparado pela aproximação afetiva.

O marcador discursivo amor romântico aparece no discurso para validar o argumento heterocêntrico, e ainda, como possibilidade de regular a conjugalidade homossexual.

Note-se, conforme se extrai do discurso emanado no STF:

\begin{abstract}
Nesse sentido, o reconhecimento do 'status' jurídico familiar da união estável, por si, alçou o afeto à condição de princípio jurídico implícito, na medida em que é ele, afeto (amor romântico, no caso), o motivo que faz com que duas pessoas decidam manter uma união estável. O elemento formador da família contemporânea é o 'amor familiar', mas é o amor romântico que dá o passo inicial para a constituição da união estável, embora haja outros argumentos a corroborar a afirmação de que o afeto é um princípio jurídico. (STF, 2011)
\end{abstract}

Como é característico da justiça registrar no nível oficial, legal e ritual o controle e essencialmente a normalização, a decisão ainda que bem-intencionada na perspectiva da intolerância sexual ao utilizar o modelo de família heterossexual para equiparação higieniza e domestica a sexualidade na esfera pública e política, a decisão do STF se equipara a um "Cavalo de Tróia" da conjugalidade romântica heterossexista.

Importante frisar que os fins do Direito Civil e do instituto do casamento representam uma regulamentação específica sobre o patrimônio, dando direitos e deveres aos cônjuges sobre a aquisição e divisão de bens, bem como o cumprimento de formalidades legais.

O modelo de família heterossexual remete à figura da ordem hierárquica da sexualidade. Essa construção conduz à interpretação do discurso na linha de uma visão tradicional do casamento que não é abandonada no contexto da decisão. $\mathrm{O}$ empreendimento da visão tradicional demonstra uma tensão entre os portadores dessa concepção. É o que se constatou logo após o julgamento do precedente judicial quando juízes se opuseram à decisão do STF. 
Há um desafio permanente de teorização para questionar a aplicação de um modelo de família binária em que o sujeito homossexual será equiparado se comportar-se dentro do modelo normativo. Luiz Mello (2006: 501) propõe:

\begin{abstract}
Ao refletir sobre uma ética sexual pluralista, seria imprescindível incorporar um conceito de variedade sexual benigna, o que contraria a ideia, prevalecente na maioria dos sistemas de pensamento sobre o sexo, de que existiria uma única sexualidade ideal, estruturante de uma organização social marcada pelo apartheid sexual, que define como não humanos os que não se enquadram nos limites da norma. Todavia, o sistema sexual não é uma estrutura monolítica.
\end{abstract}

É importante a constatação, a partir dos discursos sobre afeto e amor na decisão, em específico sobre o amor romântico, que, em nossa sociedade, depois da regulamentação do divórcio, cresceu vertiginosamente o número de heterossexuais separados e o descrédito em relação à instituição familiar. Dentro desse raciocínio, poder-se-ia perguntar por que, então, homossexuais desejam se casar e ter família se a experiência familiar é muito informal e difusa.

Para o direito, homossexuais que conviviam há décadas juntos, quando um dos parceiros adoecia ou falecia, lhe era negado o direito de acesso aos espaços privados reservados à família. As implicações acarretavam problemas com a herança quando, em muitos casos, os bens acumulados pelo casal ao longo da vida ficavam com os familiares consanguíneos.

Para ter garantido o direito à equiparação ao concedido aos casais de sexo distinto, e para a regulamentação de patrimônio dentro de uma esfera contratual, o reconhecimento dessas uniões se fez necessário. O reconhecimento exigido é de regulamentação patrimonial e transcende a construção do amor romântico idealizado pela pastoral cristã e por forças sociais interessadas na manutenção da tradição familiar.

Em diferentes partes do país, mesmo após a decisão, legisladores e a sociedade civil impõem essa perspectiva política como uma forma de manifestação da opressão àqueles que tentam transgredir a categoria de sexo e gênero, padrão nuclear moderno homem e mulher, formado por um homem instrumental, uma mulher expressiva e a socialização das crianças felizes (MELLO, 2005). Por impulso da disciplina imposta pelo discurso religioso, científico e moral, o amor foi privatizado pela instituição familiar, o amor romântico foi uma forma de higienizar o ato sexual.

O terceiro marcador discursivo é a reação conservadora. A postura impositiva de um modelo de família heterossexual corrobora a noção básica da teoria da rotulação de Becker (2008), de que a definição de regras, desvios e desviantes é um fenômeno inerentemente político, e se aplica inteiramente a outras formas de constituir família que não se enquadram no modelo binário. Grupos sociais criam o desvio ao estabelecer regras. A regra aqui estabelecida emerge de uma reação social contra aqueles que violaram a norma. Essa reação tem como base a desconstrução do modelo de família elaborada em um sistema em que, nas relações de poder, impera um regime autoritário.

O discurso conservador, no contexto da decisão, centraliza a atenção por meio dos atos de fala, utilizando o recurso da metáfora para abrandar de forma positiva o modelo da família tradicional, os valores coletivos e a compreensão do mundo pela visão heterossexual.

De acordo com o STF (2011),

Em suma, estamos a lidar com um tipo de dissenso judicial que reflete o fato histórico de que nada incomoda mais as pessoas do que a preferência sexual alheia, quando tal 
preferência já não corresponde ao padrão social da heterossexualidade. É a velha postura de reação conservadora aos que, nos insondáveis domínios do afeto, soltam por inteiro as amarras desse navio chamado coração.

A posição dos ministros revela um histórico de juízo de valor negativo frente às demandas de reconhecimento da conjugalidade homoerótica.

Da mesma forma, revela a ausência de uma linguagem apropriada para tratar das características específicas do choque em torno da questão da violência sofrida, e o contexto jurídico não apresenta um padrão técnico-científico narrativo que considere os reais fatores negativos como forma de argumento a respeito do heterossexismo, que é uma forma mais ampla de discriminação específica de um gênero em relação a outro e que pode ser associada a outras formas de discriminação como o racismo, por exemplo.

A partir da conceituação dada pelo o sociólogo Daniel Welzer Lang, o heterossexismo pode ser entendido como: "a discriminação e a opressão baseadas em uma distinção feita a propósito da orientação sexual”. O heterossexismo é a promoção incessante, pelas instituições/e ou indivíduos, da superioridade e da subordinação simulada da homossexualidade. O toma como dado que todo o mundo é heterossexual, salvo opinião em contrário.

A linguagem metafórica torna poética uma forma severa de violência em torno da construção de papéis no sistema hierárquico da sexualidade e, principalmente, na formação do centro da instituição familiar, que se descortina por meio dos saberes em torno do casamento. Da mesma forma, o aspecto político da instituição heterossexual não é revelado, à medida que não surge nos atos de fala a nomeação de onde viria essa reação conservadora, não revelando a identidade de quem se opõe a outras configurações de família, à expressão da sexualidade e de vivência da conjugalidade.

É preciso considerar todo o processo de denúncia das classificações, hierarquizações e subordinações pelas feministas e, mais recentemente, pelos movimentos LGBTs. Na lógica de que nem todo o homem é machista, temos uma abordagem que deve considerar a forma de oportunidades e privilégios construídos pela subordinação da sexualidade dentro da realidade de opressão.

A busca de compreensão pelo sentido terminológico do significado de gênero determinou, de forma preliminar, traços iniciais dos processos de classificação. "Gênero", inicialmente, designava diferenças entre os sexos, e poderia ser compreendido como um processo de classificação das espécies.

De acordo com Joan Scott (1995: 72),

o gênero é compreendido como uma forma de classificar fenômenos, um sistema socialmente consensual de distinções, uma descrição objetiva de traços inerentes. Além disso, as classificações sugerem uma relação entre as categorias que torna possível distinções ou agrupamentos separados.

De acordo com a autora, nesta classificação a opressão de gênero está vinculada ao classismo (diferença de classe), diferencialismo (diferença de raça) e determinismo (determinação biológica). Estas formas de distinção apontam para uma maior compreensão das desigualdades, sendo que elas estariam organizadas ao longo destes três eixos.

Conforme se extrai do discurso emanado no STF.

Trata-se, portanto, de um laborar normativo no sítio da mais natural diferenciação entre as duas tipologias do gênero humano, ou, numa linguagem menos antropológica e mais de lógica formal, trata-se de um laborar normativo no sítio da mais elementar diferenciação entre as duas espécies do gênero humano: a masculina e a feminina. Dicotomia culturalmente mais elaborada que a do macho e da fêmea, embora ambas as 
modalidades digam respeito ao mesmo reino animal, por oposição aos reinos vegetal e mineral. (STF, 2011)

A forma estruturante de interação que define a homossexualidade como um desvio se dá em um processo de constituição das identidades, de geração a geração, pela instituição familiar. Essa formação se estende, ainda, na escola e na sociedade, por meio de um engenhoso processo de identificação, punição e correção. Os atos de fala surgem, e as memórias são reveladas como capital simbólico de argumentação na construção dos raciocínios discursivos.

A centralidade do problema, para os conservadores, reside na tentativa de desarticulação da binariedade heterossexual, gênero. $O$ discurso, na decisão, retoma esse mecanismo, mesmo não especificando de forma sistemática essa questão. Surgem três questões importantes no discurso conservador: a heterossexualidade como política, como instituição e, por meio do discurso jurídico, como forma de construção do Estado Família. Sendo assim, Oliveira e Duque (2013: 147-148), constatam que,

\begin{abstract}
Tais segmentos reivindicando a preservação de determinados valores, frutos de uma perspectiva cristã, tendem a considerar uma série de mudanças ocorridas na sociedade brasileira como uma espécie de ameaça. Nesse sentido, não são poucas as afirmações de que "a família está ameaçada", "a sociedade vive uma crise de valores", e que existem segmentos sociais que são "inimigos da moral e dos bons costumes", portanto, da "família". Esta última compreendida como "célula mater", instituição estabelecida por Deus e, portanto, princípio vital do mundo social. Por isso, qualquer arranjo que fuja ao modelo hegemônico tende a ser rechaçado e combatido.
\end{abstract}

O conservadorismo jurídico tem origem no processo de classificação das diversas formas da sexualidade (RIOS, 2009). Essa postura reflete um problema de regulamentação dos papéis sexuais e, da mesma forma, tenta legitimar o modelo heterossexual de casal e de matrimônio para ter acesso a documentos que proporcionem validade a outros direitos que emergem dessa relação jurídica. O Estado e a Igreja tiveram papel fundamental na construção de um modelo de casamento legitimado entre o homem e a mulher, estendendo a formação do Estado pela instituição familiar (CURIEL, 2013), bem como a consagração da missão subliminar por intermédio dos preceitos religiosos. Para Butler (2003) "os poderes de normalização do Estado se tornam, porém, especialmente claros, quando se considera o quanto a contínua perplexidade sobre o parentesco condiciona e limita os debates sobre casamento”.

Assim, pensar a família dentro de uma dicotomia entre religião e política sob a perspectiva do recorte da identidade implica no retorno das bases da filosofia judaico-cristã, o que torna impossível o avanço do reconhecimento das famílias homoparentais fora do conceito de família constituída pelo homem e a mulher. Ainda assim, a decisão garante que não é possível a imposição de uma hierarquia entre heterossexuais e homossexuais com base nas práticas sexuais.

O quarto marcador discursivo é a religião/crença. Observa-se que, nos discursos do reconhecimento, a explicitação das regras retoma crenças. O discurso enaltecido pelo endogrupo revela pontos de vista, opiniões e formas de como os atores se engajam nos temas abordados. Da mesma forma, observa-se que os discursos estão a revelar essas regras e a colocar em xeque padrão da relação heterossexual como único modelo de família existente em diferentes graus de precisão, contextualizando temporalmente os discursos, mas principalmente com implicações não expressas por razões de comunicatividade de sentimentos dos atores envolvidos ou por tabus.

Vejamos: 
Por outro lado, o Direito absolutamente submetido à moral prestou serviços à perseguição e à injustiça, como demonstram episódios da Idade Média, quando uma religião específica capturou o discurso jurídico para se manter hegemônica. Como se sabe, as condenações dos Tribunais da Santa Inquisição eram cumpridas por agentes do próprio Estado - que também condenava os homossexuais, acusados de praticar a sodomia ou o "pecado nefando" que resultou, para alguns, na destruição divina da cidade de Sodoma, conforme é interpretada a narrativa bíblica. (STF, 2011)

Os atores, na decisão, remontam à trajetória histórica da homossexualidade, retomando crenças religiosas, morais e paradigmas de juízo negativo presentes, de forma contada, através do que se tem noticiado pela mídia, sem historicizar as experiências vividas por homossexuais, furtando-se a detalhes de eventos complexos de preconceito e discriminação, demonstrando graus de importância aos níveis de atenuações ou acentuações atribuídas nos significados retóricos. Isso porque é vista por muitos, ainda, como um pecado, uma doença ou um desvio moral, por fugir à normalidade binária heterossexual.

Mas não só, conforme destaca Richard Miskolci, (2007: 109):

\begin{abstract}
A sanção estatal das relações entre pessoas do mesmo sexo também traria consigo outras questões para a sociedade e para os próprios gays e lésbicas. Aparentemente, além de enfrentar o estigma da promiscuidade sexual, o casamento gay responderia ao temor coletivo da pedofilia. A parceria civil poderia diminuir oestigma de promiscuidade, mas traria à baila a possibilidade de adoção de crianças por casais homoparentais, os quais, mesmo "casados", não deixam de ser socialmente estigmatizados como possíveis "pedófilos" Historicamente, grupos sociais estigmatizados por sua religião, visão política ou orientação sexual são socialmente representados como um perigo para as crianças. No caso dos judeus, são conhecidas as lendas de que usariam crianças em rituais de sacrifício humano. Também é notória a construção da imagem dos comunistas como “devoradores de criancinhas". No caso de homens gays, a imagem de perigo os associa à pedofilia.
\end{abstract}

Os eventos são representados nas crenças, mas são também inseridos no contexto em que o pânico moral é utilizado como mecanismo de combate aos grupos que deixam transparecer a ameaça. Em seus argumentos, as bases da concepção tradicional de família de forma implícita, trazem à tona o capital simbólico dentro da lógica anatomofisiológica. Os recursos simbólicos são representados por complexos sistemas de estigmatização, como aversão fóbica presente na socialização dos indivíduos. O binômio hétero/homo (RIOS, 2009) é um critério distintivo na formação dos indivíduos e na extensão de direitos e benefícios sociais, políticos e econômicos.

O quinto marcador discursivo é a antinaturalidade. Os impactos da lógica diferenciadora estão enraizados na construção da homossexualidade como antinatural. O pressuposto para a determinação de antinaturalidade é que exista um comportamento balizador que sirva de modelo ao natural, em uma visão essencializadora. O período em que a homossexualidade era considerada pecado, e ainda é considerado em muitos países, foi marcada pela punição das relações entre pessoas do mesmo sexo em meio a um contexto no qual as codificações continham tipos penais puníveis, em que a Igreja influenciava por meio da doutrina judaicocristã a abominação a essas relações, e em que a ciência ressignificou a antinaturalidade das condutas com base no processo higienizador das relações familiares.

Segundo o conjunto de dados em que o discurso foi proferido para o STF (2011),

A aplicação da política de reconhecimento dos direitos dos parceiros homoafetivos é imperiosa, por admitir a diferença entre os indivíduos e trazer para a luz relações pessoais básicas de um segmento da sociedade que vive parte importantíssima de sua vida na sombra. Ao invés de forçar os homossexuais a viver de modo incompatível com sua personalidade, há que se acolher a existência ordinária de orientações sexuais diversas 
e acolher uma pretensão legítima de que suas relações familiares mereçam o tratamento que o ordenamento jurídico confere aos atos da vida civil praticados de boa-fé, voluntariamente e sem qualquer potencial de causar dano às partes envolvidas ou a terceiros.

É inegável que a diversidade sexual é muito abrangente em função de todo o conjunto de possibilidades de identidade de gênero e orientação sexual. A linguagem utilizada nos discursos limita-se aos casais homossexuais quando, na verdade, deveria problematizar no caso de pessoas de sexo distinto, como é o caso de uma mulher trans constituir família com outra mulher transexual, deixando de ser considerada. Ao se referir à homossexualidade, o discurso demonstra uma carência etimológica e um distanciamento linguístico próprio para se referir à diversidade sexual.

Pode-se constatar que o discurso em torno da antinaturalidade é estrategicamente definido com pudor na figura dos estereótipos que são utilizados como balizadores para a percepção de todo e qualquer comportamento que não se enquadre no modelo de sexualidade concebido pelos oradores, ou dele tente fugir. A partir do modelo heterossexual de relação, os discursos seguem a linha de tentar definir o que é a homossexualidade. Isso omitindo a diversidade de expressões assumidas por transexuais masculinos e femininos, travestis, transgêneros, que lutam pela liberdade de expressão de suas sexualidades.

Parte-se da premissa de que a homossexualidades é uma experiência social com características, representações e práticas sociais que a tornam distinta das de heterossexuais e a questão ficou por séculos nos guetos, marginalizada como expressão, sexual incompatível com a moral cristalizada e naturalizada no senso comum brasileiro. Da mesma forma, o processo gradativo de visibilização surgiu a partir de um cenário de clandestinidade em que o imaginário coletivo foi construído por meio do terror, da criminalização e do medo a homossexuais.

Há, nos discursos de reconhecimento, uma tentativa de entender o que é a homossexualidade. Essa tentativa revela, por meio do capital simbólico, a lógica dos discursos religiosos, moral e científico, em um misto de antinaturalidade e de categorização revelada na Bíblia e na leitura criacionista. O impacto da lógica diferenciadora como de estilo de vida, de escolhas certas e erradas, saudáveis e doentias, naturais e antinaturais baseado no conjunto de regras impostas tornando determinado comportamento como um desvio.

O sexto marcador discursivo é o familismo. $\mathrm{O}$ afeto tem sido reconhecido pela jurisprudência de forma efetiva e abrangente. Na família, como uma forma específica de amor próprio da conjugalidade e da parentalidade, como definidor de como a instituição familiar foi elaborada, como já referimos, na santificação do matrimônio e na missão sagrada de procriação da espécie humana.

Com base no marcador discursivo, selecionamos a amostra que segue:

\footnotetext{
Daqui se desata a nítida compreensão de que a família é, por natureza ou no plano dos fatos, vocacionalmente amorosa, parental e protetora dos respectivos membros, constituindo-se, no espaço ideal das mais duradouras, afetivas, solidárias ou espiritualizadas relações humanas de índole privada. O que a credencia como base da sociedade, pois também a sociedade se deseja assim estável, afetiva, solidária e espiritualmente estruturada (não sendo por outra razão que Rui Barbosa definia a família como "a Pátria amplificada"). (STF, 2011)
}

Ainda que se tente fugir do conceito de família tradicional, esse aparece nos discursos que os papéis são claramente definidos pela proteção do Estado, pelo cuidado indispensável à figura feminina, bancado pela figura do provedor, o que retoma a retórica normatizadora e disciplinadora da família. Ou seja, "observa-se uma verdadeira política de governamentalidade: uma economia política sobre a 
vida e as relações humanas" (OLIVEIRA e DUQUE, 2013: 142). Além disso, novas configurações familiares fora desse padrão discursivo a ser ameaçadoras pela suposta ausência das figuras principais que configuram o núcleo familiar heterossexual binário.

Os discursos, fundados numa leitura religiosa da homossexualidade, entendem que lésbicas e gays são livres para estabelecer os vínculos afetivos sexuais que quiserem, mas não teriam o direito de reivindicar a proteção do Estado para relações fundadas nos "apelos da sensualidade", e não em um "amor verdadeiro" (MELLO, 2005) por meio do casamento.

A solução, com base no discurso homoafetivo, a solução, frente à dificuldade de lidar com a questão do sexo, na tentativa de tirar o estigma envolto sobre a questão do "homossexualismo"6, foi cunhar o termo homoafetivo, o que higieniza a sexualidade envolvida nas relações homoeróticas. Simbolicamente, uma linguagem limpa da perversão sexual homossexual que retomaria o amor romântico da família tradicional.

O que revela uma dependência em relação à aprovação social e dos papéis de gênero. Além disso, "no atual cenário das lutas políticas relativas à sexualidade, para grupos religiosos fundamentalistas, o apoio institucional à conjugalidade homossexual deve ser terminantemente negado, por contrariar uma concepção de família fundada na heterossexualidade monogâmica aberta à reprodução que se pretende universal e absoluta" (MELLO, 2006).

Frente a isso, constata-se, no silenciar da lei, a dificuldade para tratar de termos como prostituição, travestilidade, liberdade sexual, sadomasoquismo e pornografia. Roger Raupp Rios (2014) complementa comparando a decisão a um "Cavalo de Tróia" da conjugalidade romântica heterossexista, uma vez que o precedente judicial não inova ao reconhecer o direito, mas ressignifica o familismo higienizado presente na legislação.

Os discursos, assim, demonstram movimentos de retomada em torno do modelo de familismo heterossexual. Os casais homoeróticos são uma possibilidade existente de família. Isso para operacionalizar o conteúdo terminológico que produz um efeito que tende a ter uma conotação negativa, como no caso do termo homoafetividade. Da mesma forma, a utilização do afeto romantizado tem por objetivo maquiar a sexualidade ainda não distante da linguagem jurídica e muito próxima da realidade das tendências de desenvolvimento dos direitos sexuais. Por outro lado, Rios (2001) apresenta a tendência de tensão entre as perspectivas universalistas e particularistas, tão presentes no discurso em análise, da luta por direitos específicos e de minorias sexuais.

Se, por um lado, há as especificidades da tutela do amor romântico, nos discursos, por outro, há o encobrimento da sexualidade no raciocínio jurídico conservador. As ideologias envolvidas em torno do abstencionismo de tratar do tema famílias homoparentais estão relacionadas, historicamente, ao modelo nuclear de família.

\footnotetext{
${ }^{6}$ Em 1974, a American Psychiatric Association retirou o termo "homossexualismo" da lista de doenças e promoveu uma revisão do conceito, que vinha sendo empregado e rebatizado como distúrbio mental. Em 1993, a Organização Mundial da Saúde (OMS) o inseriu no capítulo dos sintomas decorrentes de circunstâncias sociais, abandonando a ideia da homossexualidade como doença. A $10^{\mathrm{a}}$ revisão da CID-10, em 1995, inseriu o termo entre os transtornos psicológicos e de comportamento associados ao desenvolvimento de orientação sexual (F66), mas, no entanto, essa condição não pode ser, por si só, considerada um transtorno. No começo de 1995, a homossexualidade já não era considerada uma doença pelo Conselho Federal de Medicina. O entendimento foi utilizado a partir de 2004, no programa do Governo Federal denominado "Brasil sem Homofobia". Segundo Trevisan (2007), em 1999, o Conselho Federal de Psicologia (CFP) editou a resolução CFP n ${ }^{\circ}$ 001/99, de 22 de março de 1999, que estabelece as normas de atuação para os psicólogos em relação à orientação sexual. A partir dessa data, não era mais adequado referir-se ao grupo de homossexuais com o termo "homossexualismo", que designa doença, bem como se proibiu qualquer tentativa de tratamento psicológico para a sua cura.
} 
Não se trata apenas de um ingênuo esquecimento do legislador, e sim de uma política da sexualidade heterossexual hegemônica. Termos como identidade de gênero ou orientação sexual são vetados nos debates no Congresso Nacional. Não por acaso, após a decisão foi votado e aprovado o Estatuto da Família que retoma a forma literal da lei prevista na Constituição Federal.

Em 2013, houve um debate, na Câmara dos Deputados, sobre um projeto protocolado pelo deputado Pastor Eurico (PSB-PE), que buscava derrubar a Resolução de 1999 do Conselho de Psicologia, que próibe tratamentos destinados a "reverter a homossexualidade", a chamada "cura gay". O argumento para a derrubada da resolução do Conselho de Psicologia acionava o capital simbólico do discurso religioso, argumentando que inexistem bases científicas para explicar a homossexualidade; desconsiderando os estudos da psicologia que referem o contrário.

Em outras palavras, segundo Luiz Mello (2005: 201), "as lutas em torno do reconhecimento social e jurídico da dimensão familiar das uniões homossexuais estão constitutivamente associadas à afirmação/negação do mito da complementaridade dos sexos e dos gêneros", o que reduz à binariedade homem-mulher a competência moral e social de desempenhar as funções atribuídas à instituição familiar.

Há também, entretanto, o discurso liberal de reconhecimento (MECCIA, 2010) que serve de aporte para entender os avanços que existem em torno do reconhecimento das uniões entre pessoas do mesmo sexo. Trata-se de um discurso que tende a adaptar a moral comunitária à concessão de permissão ao indivíduo - o que revela, por um lado, um problema e, por outro, vai ao encontro da questão da liberdade do indivíduo.

É o mesmo que dizer que a decisão aprisiona pessoas do mesmo sexo a se enquadrar no modelo de casamento heterossexual e é o que define Roger Raupp Rios (2001) ao afirmar que essa modalidade de discurso judicial se caracteriza pela conjunção de duas modalidades de ideologia: o assimilacionismo e o familismo.

\section{Conclusão}

Até a decisão se considerava normal o entendimento de que casamento era entre homem e mulher. A lei fala exatamente isso. Isso em um cenário em que o legislador continua negando direitos as relações homoeróticas ao não legislar a respeito. Até que ponto se permite a intervenção na questão da sexualidade homossexual sendo que é a sociedade que está em questão?

O reconhecimento equiparado tem impacto direto na construção da identidade dentro das diferentes culturas LGBTs. De forma inédita, a heterossexualidade entrou nos debates jurídicos dando sentido à existência da homossexualidade como de fato um debate democrático da família. O que se questiona, a partir daí, são os polos em que se encontram uma ou outra. Se a heterossexualidade é o vértice em cujo entorno estão todos os outros núcleos familiares, se está diante de um sistema hegemônico.

O que se interroga é a heterossexualidade estar associada a um padrão normal que serve como modelo para equiparação, nesse caso, não há abertura suficiente para um avanço efetivo no panorama dos direitos sexuais. Como contemplar juridicamente outros modelos de parentalidade e conjugalidade que ainda não foram considerados na decisão como família de amigos cujo vínculo não passa pela atividade sexual. 
Razoável que se espere capacidade interpretativa no sentido de que a imposição de um único padrão sexual não é compatível com princípios democráticos de um Estado de Direito. Para que haja verdadeiros avanços com relação à família não se deve imaginar que seja possível não reconhecer outras formas tanto de relação como de organização social dentro de sua própria identidade fazendo com que padrões de conduta estigmatizados sejam amplamente debatidos e respeitados em suas características e em seus direitos fundamentais.

Recebido em 2 de maio de 2019.

Aceito em 10 de fevereiro de 2020.

\section{Referências}

BECKER, Howard S. Outsiders. Estudos de sociologia do desvio. Rio de Janeiro: Zahar, 2008.

BRASIL. Constituição da República Federativa do Brasil. Brasília: Centro Gráfico Senado Federal, 1988.

BRASIL. Supremo Tribunal Federal. Ação Direta de Inconstitucionalidade 4.277. Decisão Distrito Federal: STF, 5 maio 2011. Disponível em: < redir.stf.jus.br/paginadorpub/paginador.jsp?docTP=AC\&docID...> . Acesso em: 6 jun. 2014.

BUNCHAFT, Maria Eugenia; CRISTIANETTI, Jéssica. O julgamento da ADI 4277 no STF: uma crítica ao binarismo sexual à luz do debate Fraser-Honneth. Revista Direito e Liberade, 18 (2): 51-84, 2016.

BUTLER, Judith. "Corpos que pesam: sobre os limites discursivos do 'sexo"'. In: LOURO, Guacira Lopes (Org.). O corpo educado: pedagogias da sexualidade. Belo Horizonte: Autêntica, 2001.

BUTLER, Judith. O parentesco é sempre tido como heterossexual? Cadernos Pagu, 21: 219-260, 2003.

CORREAS, Oscar. Introdução à Sociologia Jurídica. Trad. Carlos Souza Coelho. Porto Alegre: Crítica Jurídica, 1996.

COSTA, Jurandir Freire. Ordem médica e norma familiar. Rio de Janeiro: Edições Graal, 1999.

CURIEL, Ochy. La nación heterosexual: análisis del discurso jurídico y el régimen heterosexual desde la antropología de la dominación. Bogotá: Brecha Lésbica y en la frontera, 2013.

DIJK, Teun A. van. Discurso e poder. São Paulo: Contexto, 2012.

FAIRCLOUGH, N. Discurso e mudança social. Brasília: Editora da UnB, 2001 
FOUCAULT, Michel. História da sexualidade: a vontade de saber. Vol. 1. Rio de Janeiro: Edições Graal, 1988.

FRASER, Nancy. Reconhecimento sem Ética? Revista Lua Nova, 70: 101-138, 2007.

FRY, Peter. "Da hierarquia à igualdade: a construção histórica da homossexualidade no Brasil”. In: FRY, Peter. Para Inglês ver: identidade e política na cultura brasileira. Rio de Janeiro: Zahar, 1982. pp. 87-115.

GIDDENS, Anthony. Sociologia. Tradução Alessandra Figueireto et al. $4^{\mathrm{a}}$. ed. Lisboa: Fundação Calouste Gulbenkian, 2004.

GOFFMAN, Evering. Estigma: notas sobre a manipulação da identidade deteriorada. Tradução Márcia bandeira de mello Leite Nunes. Rio de Janeiro: Guanabara, 1988.

HONNETH, Axel. Luta por reconhecimento: a gramática moral dos conflitos sociais. São Paulo: Edições 34, 2014.

HONNETH, Axel. "Redistribution as Recognition: a Response to Nancy Fraser". In: FRASER, Nancy; HONNETH, Axel. Redistribution or Recognition. Londres: Verso, 2003.

MACHADO, João Baptista. Introdução ao direito e ao discurso legitimador. Coimbra: Almedina, 1991.

MADALENO, Rolf. Curso de direito de família. 6. ed. Rio de Janeiro: Forense, 2015.

MECCIA, Ernesto. Los peregrinos a la ley. Una tipología de discursos sobre expertos, jueces y legisladores en torno a las demandas LGTB y al matrimonio igualitario. In: Matrimonio igualitario. Perspectivas sociales, políticas y jurídicas. Buenos Aires: Eudeba, 2010.

MELLO, Luiz. Different families: the social construction of homosexual conjugality in Brazil. Cadernos Pagu, 24: 197-225, 2005.

MELLO, Luiz. Familismo (anti) homossexual e regulação da cidadania no Brasil. Estudos Feministas, 14 (2): 497-508, 2006.

MISKOLCI, Richard. Moral panics and social control: reflections about gay marriage. Cadernos Pagu, 28: 101-128, 2007.

NUERNBERG, Adriano Henrique. Uma análise crítica do direito à diferença. Estudos Feministas, 9 (1): 299-300, 2001.

OLIVEIRA, E. A. de. Políticas do Corpo, políticas da vida: Uma Análise sobre o Estatuto da família no Brasil. Nanduty, 4: 132-153, 2013.

PARISOTTO, L. Diferenças de gênero no desenvolvimento sexual: integração dos paradigmas biológicos, psicanalítico e evolucionista. Revista de Psiquiatria, 25 (1): 75-87, 2003.

RIOS, Roger Raupp. A homossexualidade no direito. Porto Alegre: Esmafe, 2001.

RIOS, Roger Raupp. "Homofobia na perspectiva dos direitos humanos e no contexto dos estudos sobre preconceito e discriminação". In: JUNQUEIRA, Rogério Diniz (org.). Diversidade Sexual na Educação: problematização sobre a homofobia nas escolas. Brasília: Unesco, 2009. pp. 53-83. 
RIOS, Roger Raupp. "Direitos sexuais, uniões homossexuais e a decisão do Supremo Tribunal Federal (ADPF $\mathrm{n}^{0} 132$ - RJ e ADI 4.277)". In: RIOS, Roger Raupp; GOLIN, Célio; LEIVAS, Paulo Gilberto Logo (orgs.). Homossexualidade e Direitos Sexuais: Reflexões a partir da decisão do STF. Porto Alegre: Sulina, 2011. pp. 69-113.

RIOS, Roger Raupp; OLIVEIRA, Rosa Maria Rodrigues de. "Direitos sexuais e heterossexismo: identidades sexuais discursos judiciais no Brasil". In: MISKOLCI, Richard; PELÚCIO, Larissa (orgs.). Discursos fora de ordem: sexualidade, saberes e direitos. São Paulo: Annablume, 2012.

RIOS, Roger Raupp. “A criminalização e a representação midiática da homofobia: relações com a trajetória dos direitos sexuais no Brasil”. In: SEFFNER, Fernando; CAETANO, Marcio (orgs.). Cenas latino-americanas da diversidade sexual e de gênero: Práticas, pedagogias e políticas públicas. Rio Grande: Ed. da FURG, 2015. pp. 73-96.

SCOTT, Joan Wallach. Gênero: uma categoria útil de análise histórica. Educação e Realidade, 20 (2) : 71-99, 1995.

VELHO, Gilberto. Desvio e divergência: uma crítica da patologia social. Rio de Janeiro: Jorge Zahar, 2003.

WODAK, R. Do que trata a ACD: um resumo de sua história, conceitos importantes e seus desenvolvimentos. Linguagem em (Dis)curso, 24 (ESPECIAL): 223$243,2004$. 